\title{
Balancing fittings in a water heating system
}

\author{
Olesya Averyanova ${ }^{1}$, Aleksandra Amelina ${ }^{1 *}$, Pavel Amelin ${ }^{1}$, Aleksandra Makeeva ${ }^{1}$, Sergej Manovitskij ${ }^{2}$, and Ernest \\ Ivanov $^{1}$
}

${ }^{1}$ Peter the Great St. Petersburg Polytechnic University, Polytechnicheskaya 29, 195251 St. Petersburg, Russia

${ }^{2} \mathrm{~N}$-Systems Corp., Optikov Street 4, 197374 Saint-Petersburg, Russia

\begin{abstract}
Energy conservation and improving energy efficiency are priority areas for the development of the global economy. The need to increase the energy efficiency of the engineering equipment of buildings is due to both the requirements to reduce the energy consumption of buildings in general, and the increase in the proportion of energy-consuming climate systems used in modern construction. In large modern office, hotel and residential complexes to achieve the greatest energy efficiency it is necessary to use various technical solutions. The main element of an energy-efficient heating system is regulation. Balancing devices allow to not only balance and tune the system at any time of operational period but also serve as stop valves during reparation and diagnostics. Determination of energy savings bases on the average value heat consumption before and after modernization, depending on the type of installed valves or their combination. The focus of the work is hydraulic calculation of the heating system - the authors conduct research on the effect of differently balancing fittings on the hydraulics of the heating system.
\end{abstract}

\section{Introduction}

According to the Federal Law "About energy saving and increasing energy efficiency and on making changes certain legislative acts of the Russian Federation" dated November 23, 2009 № 261-FZ (latest edition), there is a need to increase energy efficiency based on modernization, technological development and transition to a rational and environmentally responsible use of energy resources.

The energy efficiency of the heating system consists of the effective use of the source fuel energy potential, i.e. the heating system must use the maximum amount of energy from the source fuel, while the rooms should not overheat or cool. In decentralized heating (for example, a small cottage) it is possible to achieve a comfortable microclimate much easier in view of its size. However, as in large modern office, hotel and residential complexes, to achieve the greatest energy efficiency of the system, it is necessary to use various technical solutions to achieve the greatest energy efficiency of the system [1].

The main element of an energy-efficient heating system is its regulation, that allows to supply the heat carrier to the heating devices in sufficient quantities to ensure the heat balance of the rooms with a changing outdoor temperature and an indoor air temperature set by a room user (within the normalized range). For this functional purpose of the room). Balancing devices are used to perform the regulation of heating system, they allow not only to balance and tune the system at any time of its installation but also serve as stop valves during repairment and diagnostics [2, 3].

In this paper, three types of balancing devices are considered: a throttling orifice, a manual balancing valve, and an automatic balancing valve $[4,5]$.

- The throttling orifice is a steel disc with a hole in the middle. The flow is regulated by changing the diameter of the inner hole.

- Manual balancing valve - the changes in the position of the spindle drives the working cone, that reduces or increases the diameter of the coolant section.

- The automatic balancing valve is set to the maximum water flow rate. The pressure will increase as a coolant consumption decrease with changes on radiator thermostat. At that moment the capillary tube comes into effect. It uses an automatic valve that instantly analyzes the differential pressure.

Balancing valves should be installed to divide the system into modules that can be balanced independently of the rest of the system, i.e. each branch, each riser and each source must be equipped with a balancing valve.

The purpose of the study is to develop a methodology for choosing a technical solution for balancing heating systems based on energy efficiency indicators of the system. 


\section{Materials and methods}

\subsection{General data}

The object of study is a two-pipe heating system with a lower wiring of the main pipelines in the residential three-story two-entrance house with unheated basement and attic. There is water as a heat carrier with a temperature in the supply pipe of $80^{\circ} \mathrm{C}$ and a return of $60{ }^{\circ} \mathrm{C}$ is taken as a heat carrier. Types of pipes - ordinary steel water-gas piping according to GOST 3262-75 $\mathrm{P}_{\mathrm{N}}$ $1.0 \mathrm{MPa}, \mathrm{T}_{\max } 150^{\circ} \mathrm{C}$.

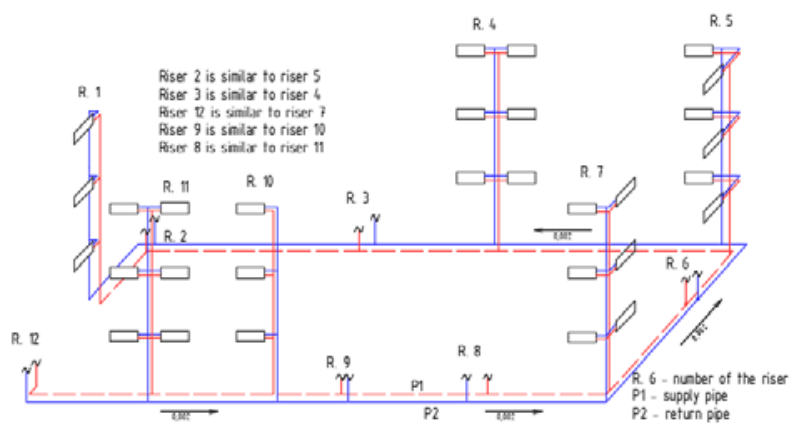

Fig. 1. Design scheme of the investigated heating system

\subsection{Hydraulic calculation of the heating system manually}

Following tasks should be performed during hydraulic calculation:

- $\quad$ determination of the pipelines diameters in sections of the heating system, considering the recommended and economically feasible speeds of the coolant (coolant speed 0.3-0.7 m/s);

- calculation of hydraulic pressure losses in system sections;

- $\quad$ hydraulic linkage of parallel instrument and other branches of the system, using control valves for dynamic balancing during unsteady thermal and hydraulic modes of the heating system;

- determination of pressure loss and flow rate in the heating system.

The heat load of the design section is equal to the heat flux that must transfer (on the supply pipelines) or transferred (on the return pipelines) the coolant that is transported on the site. The flow rate of the coolant in the area is determined by the formula (1):

$$
G_{i-j}=\frac{3.6 \cdot Q_{i-j}}{c \cdot\left(t_{\gamma}-t_{0}\right)}=\frac{0.86 \cdot Q_{i-j}}{t_{\gamma}-t_{0}},
$$

where $\mathrm{c}=4.2 \mathrm{~kJ} /\left(\mathrm{kg} \cdot{ }^{\circ} \mathrm{C}\right)$ is the specific heat capacity of water;

$t_{\gamma}$ — rated temperature of the hot fluid in the heating system, ${ }^{\circ} \mathrm{C}$;

$t_{0}$ - rated temperature of the cooled coolant in the heating system, ${ }^{\circ} \mathrm{C}$

The internal diameter of the pipeline is determined according to the table, knowing the flow rate of the coolant in this section and the temperature difference of the supply and return pipes.

Pressure loss on an arbitrary section of the system is the sum of two components: pressure loss on hydraulic friction during transportation of the coolant in the pipe and pressure loss in local resistances.

$$
\square P=S \cdot G^{2} \text {, }
$$

where $G$ - mass flow rate of the coolant of the section, $\mathrm{kg} / \mathrm{h}$;

$\mathrm{S}$ - the hydraulic resistance characteristic of the system section, $\mathrm{Pa} /(\mathrm{kg} / \mathrm{h})^{2}$, calculated by the formula (3):

$$
S=A \cdot \xi_{a d j}=A \cdot\left(\frac{\lambda}{d} \cdot l+\sum \xi\right),
$$

where $A$ - specific dynamic pressure, $\mathrm{Pa} /(\mathrm{kg} / \mathrm{h})^{2}$;

$\xi_{a d j}$ - adjusted coefficient of local resistance of the section.

The determination of the coefficient of hydraulic friction is carried out according to the formula (4):

$$
\lambda=0.11 \cdot\left(\frac{68}{R_{\mathrm{e}}}+\frac{k_{e}}{d}\right)^{0.25},
$$

where $R e$ - Reynolds number;

$k_{e}$ - equivalent pipe roughness, mm.

The specific dynamic pressure in the pipeline with fixed diameter is the dynamic pressure created by the flowing coolant at a mass flow rate of $1 \mathrm{~kg} / \mathrm{h}$ determines by the manufacturer of the pipeline, or by the formula (5):

$$
A=\frac{\rho \cdot v^{2}}{2 \cdot G^{2}}=\frac{1}{2 \cdot \rho\left(\frac{\pi \cdot d^{2}}{4} \cdot 3600\right)^{2}}=\frac{6.021}{\rho \cdot d^{4}},
$$

The hydrodynamic characteristics of the pipes can be determined from the table provided by the manufacturer.

The hydraulic resistance of the heating system is defined as the sum of the pressure losses in the sections.

$$
\Delta P_{H S}=\sum \Delta P_{i-j},
$$

The diameter of the throttling orifice hole is determined by the formula (7):

$$
d_{0}=3.16 \cdot \sqrt[4]{\frac{G^{2}}{\Delta P}},
$$

where $G$ - mass flow rate of the coolant of the section, $\mathrm{kg} / \mathrm{h}$;

$\Delta \mathrm{P}_{\mathrm{HS}}$ - pressure loss in the regulation section, $\mathrm{MPa}$.

\subsection{Hydraulic calculation in the program}

Hydraulic calculation of the heating system can be done manually, as well as using software that performs hydraulic calculation, selection of the diameters of the fittings, as well as heating devices, for example, AUDITOR CO 6.0, AUDITOR CO 3.8, KAN CO 3.8, HERZ CO 3.8, DAFFOSS CO 3.8, Rehau CO3.8 etc.

In this work, the hydraulic calculation is performed in the program Rehau CO 3.8. Before starting the calculation, general data and a detailed flat diagram of the heating system of the entire building with heat losses and temperatures in each room, pipe lengths and necessary fittings should be entered. 


\section{Results}

The calculation in the program was carried out with various variations of balancing reinforcement (Table 1):

1. Without any balancing and shutoff valves;

2. Automatic balancing fittings on risers of the system - as reinforcement selected AB-PM - differential pressure and direct flow control;

3. Manual balancing valve and globe valve on risers, as reinforcement selected USV-I, shut off valve with smooth presetting, female thread;

4. Balancing fittings in front of the heating devices direct thermostatic valve with presetting, RTR-N, as well as a direct shut-off valve with the possibility of connecting a drain valve, designed to turn off a separate heating device for dismantling or maintenance without draining the entire system;

5. The combination of balancing valves № 1 : automatic adjustment on risers and manual in front of heating appliances;

6. The combination of balancing valves №2: manual adjustment on risers and manual adjustment in front of radiators;

7. Throttling orifice on the risers of the system.

Table 1 presents the summary calculation results.

Table 1. Calculation results

\begin{tabular}{|c|c|c|}
\hline Settlement option numbers & $\begin{array}{c}\text { Hydrauli } \\
\text { c } \\
\text { resistanc } \\
\text { e of } \\
\text { equipme } \\
\text { nt and } \\
\text { heat } \\
\text { source, } \\
\text { Pa }\end{array}$ & $\begin{array}{c}\text { Excessiv } \\
\text { e heat in } \\
\text { heated } \\
\text { rooms, } \\
\text { W }\end{array}$ \\
\hline 1. Without any valve & 17400 & 949 \\
\hline 2. AB-PM & 36902 & 947 \\
\hline 3. USV-I and globe valve & 20627 & 947 \\
\hline 4. RTR-N and RLV & 26273 & 898 \\
\hline 5. AB-PM, RTR-N and RLV & 31527 & 898 \\
\hline 6. USV-I, globe valve, RTR-N and & 38902 & 898 \\
\hline RLV & 17065 & 890 \\
\hline 8. Throttling orifice & 17703 & - \\
\hline
\end{tabular}

\subsection{Comparison of the results}

Fig. 2 and 3 show histograms of the obtained results. Numbers of variants of calculations correspond to accepted in table 1.

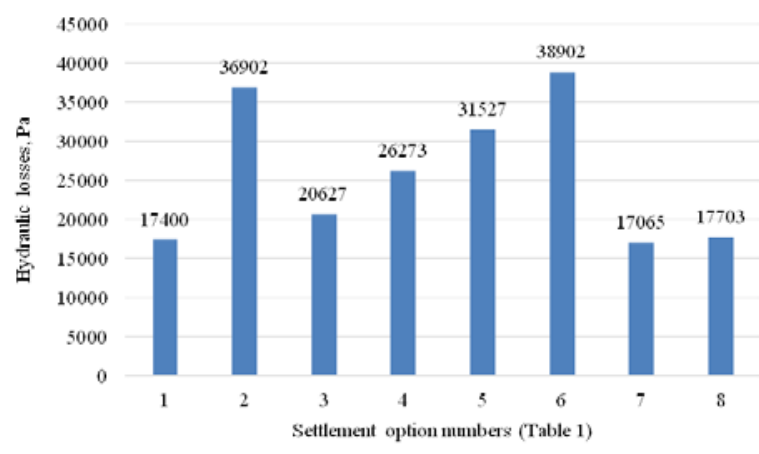

Fig. 2. A histogram of the obtained results of hydraulic resistance calculations

As we can see from the results obtained, the installation of balancing valves increases the hydraulic resistance of the system. The software calculation does not consider the resistance caused by the installation of throttling orifice.

The percentage of calculations in relation to manual is:

$$
\Delta=\frac{\Delta P_{8}-\Delta P_{1}}{\Delta P}=\frac{17703-17400}{17703}=1.7 \% ，
$$

where $\Delta P_{8}$ - hydraulic resistance of equipment and heat source of the calculation option №8 (manual calculation), $\mathrm{Pa}$;

$\Delta P_{1}$ - hydraulic resistance of equipment and heat source of the calculation option №1 (calculation by program Rehau CO 3.8 without any valve), Pa.

The discrepancy between manual hydraulic calculation and hydraulic calculation without reinforcement is due to roundings that were used in manual calculations.

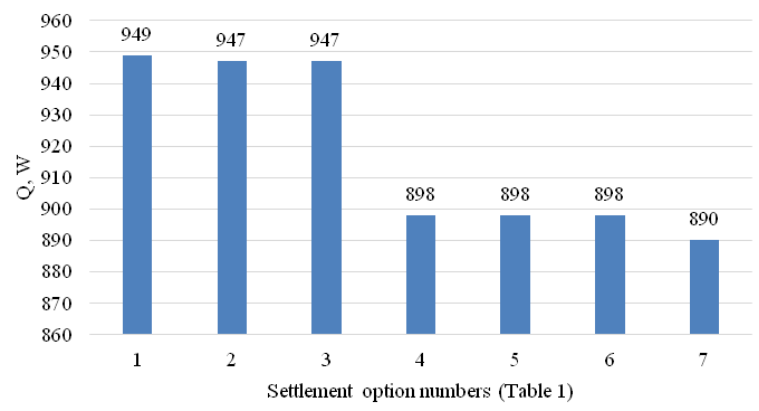

Fig. 3. A histogram of the results of calculations for overheating of premises

As we can see from the results obtained, the system overheats the most in the absence of any balancing valves. The heating system is not energy efficient. The least hydraulic resistance and overheating of the system is observed when the installation of throttling orifice in each riser of the heating system. But with this design option, users of the heating system cannot control the heat transfer of the heater.

$$
\Delta=\frac{\Delta Q_{1}-\Delta Q_{7}}{\Delta Q_{1}}=\frac{949-890}{949}=6.2 \% ，
$$


where $\Delta Q_{1}$ - excessive heat in heated rooms of the calculation option №1 (calculation by program Rehau CO 3.8 without any valve), $\mathrm{W}$;

$\Delta Q_{7}$ - excessive heat in heated rooms of the calculation option №7 (calculation by program Rehau CO 3.8 with throttling orifice), W;

Energy savings with balancing with throttling orifice prevail over calculation option № 1 without the use of fittings by $6.2 \%$.

Also, an energy efficient option is the calculation with balancing on risers and radiators. In this calculation, we observe the greatest hydraulic losses, but the smallest overheating of the system and the ability of users to adjust the comfortable temperature in the rooms by adjusting the pre-setting of the heating devices.

$$
\Delta=\frac{\Delta Q_{1}-\Delta Q_{4}}{\Delta Q_{1}}=\frac{949-898}{949}=5.4 \%
$$

where $\Delta Q_{4}$ - excessive heat in heated rooms of the calculation option №4 (calculation by program Rehau CO 3.8 with balancing fittings in front of the heating devices - RTR-N and RLV), W;

Energy savings with balancing on risers and radiators prevail by $5.4 \%$ over a heating system in where there are no balancing fittings.

\section{Discussion}

In [4-6], field studies of the energy efficiency of heating systems using balancing valves of various types were carried out. According to the research results, energy savings were determined based on the average heat consumption before and after modernization, depending on the type of installed valves or their combination. In [7], the results of an experimental study are presented showing that the use of manual balancing valves reduces the energy efficiency of the system. This circumstance is caused by the fact that the comfort temperature is not maintained inside that leads to overheating and excessive fuel consumption. Works [8-12] show the positive use of thermostatic valves on heating radiators. And the article [13] gives the analysis of the control quality of a thermostatic valve. In [14], studies were conducted on the effect of balancing valves on the flow shape and conclusions were drawn that the changes in the flow shape are insignificant.

The problem of energy efficiency of the heating system is also considered in [15-18].

In [19, 20], show the example is given of using automatic balancing fittings, which reduced the energy consumption by pumps of the heating system by $14 \%$.

In [21, 22], the authors conduct research on the effect of balancing fittings on the hydraulics of the heating system. In this article, a similar conclusion is obtained that shut-off and control valves increase the hydraulic losses of the system, but at the same time increase its energy efficiency.

The energy efficiency of the building will heal not only from the energy efficiency of engineering systems, but also from the building envelope. Comparison of materials and proposals for improving the energy efficiency of the entire building are considered in [2325].

Article [26] says that it is necessary to increase the energy efficiency of not only new buildings under construction, but also to invest in improving the energy efficiency of already constructed buildings. And the work [27] analyzes the development of regulatory and legislative support for the energy efficiency of buildings in the Russian Federation.

\section{Conclusion}

In this paper, the main attention is paid to the hydraulic calculation of the heating system.

1. According to the results of the calculations, the smallest hydraulic resistance is possessed by a system that is balanced by throttling orifice.

2. The most energy-efficient is the system that is regulated by throttling orifices set on the risers.

3. From the comfort of use as well as high energy efficiency point of view designed systems № 4, 5, 6 that have adjustments on the risers and radiators are the best.

Balancing valves add additional resistance to the pipeline, but at the same time regulates the coolant, making the system more energy efficient. Thus, the use of a balanced heating system will allow people living in large residential complexes to set their own comfortable indoor temperature by adjusting the thermostatic valve on the heating radiator. In the future, when the meter is installed on the radiator it will allow to save finances.

Also, the installation of throttling orifice regulates the system in the way that the coolant with the specified temperature parameters comes to the most remote riser, without cooling down.

\section{References}

1.A. Frolov, E. Spiridonova, A. Lipatov,: Use of balancing valves in heating systems. Research in construction, heat and gas supply and energy supply, 317-320 (2016)

2.CIMBEIO METOD Method of balancing the heating system using balancing valves CIMERIO heating https://www.termoros-

spb.ru/upload/docs/Passport_Instruction/Cimberio/Cimb erio_Metod.pdf last accessed 2019/10/03;

3. Balancing valve to adjust the system https://otivent.com/balansirovochnyj-klapan-dlja-sistemotoplenija last accessed 2019/10/03;

4.T. Cholewa, I. Balen, A. Siuta-Olcha,: On the influence of local and zonal hydraulic balancing of heating system on energy savings in existing buildings Long term experimental research. Energy and Buildings 179, 156-164 (2018)

5.C. Zhou, L. Ni, J. Li, Z. Lin, J. Wang, X. Fu, Y. Yao,: Air-source heat pump heating system with a new temperature and hydraulic-balance control strategy: A field experiment in a teaching building. Renewable Energy 141, 148-161 (2019) 
6. B. Xu, L. Fu, H. Di,: Dynamic simulation of space heating systems with radiators controlled by TRVs in buildings. Energy and Buildings 40, 9, 1755-1764 (2008)

7.Z. Liao, M. Swainson, A.L. Dexter,: On the control of heating systems in the UK. Building and Environment 40, 3, 343-351 (2005)

8. M. Maivel, J. Kurnitski,: Heating system return temperature effect on heat pump performance. Energy and Buildings 94, 71-79 (2015)

9.M. Tunzi, D. S. Østergaard, S. Svendsen, R. Boukhanouf, E. Cooper: Method to investigate and plan the application of low temperature district heating to existing hydraulic radiator systems in existing buildings. Energy 113, 413-421 (2016)

10. Y. Wang, S. You, X. Zheng, H. Zhang,: Accurate model reduction and control of radiator for performance enhancement of room heating system. Energy and Buildings 138, 415-431 (2017)

11. D.P. Muniak,: Sizing the Radiator Control Valve Taking Account of Inner Authority. Procedia Engineering 157, 98-105 (2016)

12. T. Cholewa, A. Siuta-Olcha, C. A. Balaras: Actual energy savings from the use of thermostatic radiator valves in residential buildings - Long-term field evaluation. Energy and Buildings 151, 487-493 (2017)

13. J. Seifert, M. Knorr, A. Meinzenbach, F. Bitter, N. Gregersen, T. Krogh,: Review of thermostatic control valves in the European standardization system of the EN 15316-2/EN 215. Energy and Buildings 125, 5565 (2016)

14. M. Pietrzak, S. Witczak,: Experimental study of air-oil-water flow in a balancing valve. Journal of Petroleum Science and Engineering 133, 12-17 (2015)

15. T. Yu, X. Wang, J. Ji, S. Zhao,: Energy efficiency of distributed energy system based on central heating network. Procedia Engineering 205, 2171-2175 (2017)

16. Y. Shimoda, T. Nagota, N. Isayama, M. Mizuno,: Verification of energy efficiency of district heating and cooling system by simulation considering design and operation parameters. Building and Environment 43, 4, 569-577 (2008)

17. O. Pruissen, A. Togt, E. Werkmana,: Energy Efficiency Comparison of a Centralized and a Multiagent Market Based Heating System in a Field Test. Energy Procedia 62, 170-179 (2014)

18. Q. Zhang, X. Zhang, D. Sun, G. Wang,: Municipal space heating using a ground source absorption heat pump driven by an urban heating system. Geothermics 78, 224-232 (2019)

19. D. Shkol'nikov,: In search of balance. Heating system. 54-58 (2013)

20. A. Frolov, E. Spiridonova, A. Lipatov,: Peculiarities of application of balancing valves in heating systems. Research in construction, heat and gas supply and energy supply 235-237 (2017)

21. L. Makhov, C. Usikov,: Hydraulic mode of water heating system. Plumbing, heating, air conditioning, 72-73 (2013)

22. J.Y. Qian, Z.X. Gao, J.-K. Wang, Z.-J. Jin,: Experimental and numerical analysis of spring stiffness on flow and valve core movement in pilot control globe valve. International Journal of Hydrogen Energy 42, 27, 17192-17201 (2017)

23. F.G. Tarasevskii, V.A. Derizemlya, Yu.A. Ibraeva, D.V. Nemova, Methods for increasing energy efficiency of residential building. collection of reports of youth scientific and practical conference within the frame XLIII week of science SPbPU, 80-82 (2014)

24. A.E. Kiryudcheva, V.V. Shishkina, D.V. Nemova, Energy efficiency of protective facilities of public buildings. Construction of unique buildings and constructions 5(44), 19-30 (2016)

25. N.I. Vatin, D.V. Nemova, A.S. Gorshkov, Comparative analysis of loss of heat energy and operating heating costs for a country private house at various minimum requirements to the heat protection level of protective designs. Building materials, equipment, technologies of the XXI century 1(168), 3639 (2013)

26. A.S. Gorshkov, P.P. Rymkevich, D.V. Nemova, N.I. Vatin, Economic efficiency of investments in energy saving. Engineering systems. ABOK - NorthWest 3, 32-36 (2014)

27. A.S. Gorshkov, N.I. Vatin, P.P. Rymkevich, Implementation of the state program to enhance the energy efficiency of residential and public buildings. Building materials, equipment, technologies of the XXI century 1(180), 39-46 (2014) 